\title{
BMJ Open Household food insecurity and its association with self-reported male perpetration of intimate partner violence: a survey of two districts in central and western Uganda
}

\author{
George Awungafac (D) , ${ }^{1}$ Stephen Mugamba, ${ }^{2}$ Fred Nalugoda, ${ }^{2}$ \\ Carl Fredrik Sjöland (1) , ${ }^{1}$ Godfrey Kigozi, ${ }^{2}$ Susanne Rautiainen, ${ }^{1}$ \\ Robert Bulamba Malyabe, ${ }^{2}$ Leo Ziegel, ${ }^{1}$ Gertrude Nakigozi, ${ }^{2}$ \\ Grace Kigozi Nalwoga, ${ }^{2}$ Emmanuel Kyasanku, ${ }^{2}$ James Nkale, ${ }^{2}$ Stephen Watya, ${ }^{2}$ \\ Anna Mia Ekström, ${ }^{1}$ Anna Kågesten ${ }^{1}$
}

To cite: Awungafac G, Mugamba S, Nalugoda F, et al. Household food insecurity and its association with self-reported male perpetration of intimate partner violence: a survey of two districts in central and western Uganda. BMJ Open 2021;11:e045427. doi:10.1136/ bmjopen-2020-045427

- Prepublication history and additional materials for this paper are available online. To view these files, please visit the journal online (http://dx.doi. org/10.1136/bmjopen-2020045427).

Received 06 0ctober 2020 Revised 11 March 2021 Accepted 15 March 2021

A) Check for updates

(c) Author(s) (or their employer(s)) 2021. Re-use permitted under CC BY. Published by BMJ.

${ }^{1}$ Department of Global Public Health, Karolinska Institute, Stockholm, Sweden

${ }^{2}$ Africa Medical and Behavioural Science Organization, Kampala, Uganda

Correspondence to Dr George Awungafac; awungafacg@yahoo.com

\section{ABSTRACT}

Objectives This study aimed to determine the lifetime prevalence of male-perpetrated intimate partner violence (IPV), and to assess the association with food insecurity, sociodemographic factors and health risk behaviours in Uganda in the year preceding COVID-19-associated lockdowns.

Design Population-based, cross-sectional household survey.

Setting Urban, semiurban and rural communities of the Wakiso and Hoima districts in Uganda.

Participants A total of $\mathrm{N}=2014$ males aged $13-80$ years participated in the survey. The current study included males who reported having ever been in a sexual union and responded to the IPV questions ( $\mathrm{N}=1314)$.

Measures Data were collected face-to-face from May 2018 to July 2019 using an interviewer-mediated questionnaire. Lifetime IPV perpetration was measured as 'no physical and/or sexual IPV', 'physical' versus 'sexual violence only', and 'physical and sexual violence'. Pastyear food insecurity was measured through the Food Insecurity Experience Scale and categorised into 'none', 'Iow' and 'high'. Multinomial logistic regression was used to determine the crude and adjusted relative risk ratios (aRRRs) of IPV perpetration in relation to self-reported food insecurity, adjusting for sociodemographic and health risk behaviours.

Results The prevalence of self-reported lifetime IPV perpetration was $14.6 \%$ for physical and $6.5 \%$ for sexual violence, while $5.3 \%$ reported to have perpetrated both physical and sexual IPV. Most (75.7\%) males reported no food insecurity, followed by low $(20.7 \%)$ and high (3.6\%) food insecurity. In adjusted models, food insecurity was associated with increased risk of having perpetrated both physical and sexual violence (aRRR $=2.57,95 \% \mathrm{Cl} 1.52$ to 4.32). IPV perpetration was also independently associated with having had more than one lifetime sexual partner and drinking alcohol, but not with education level or religion.

Conclusion This study suggests that food insecurity is associated with male IPV perpetration, and more
Strengths and limitations of this study

- This is the first study to investigate the association between lifetime male perpetration of intimate partner violence (IPV) with food insecurity in Uganda.

- We included a population-based, diverse and representative sample of participants from different geographical areas (rural, semiurban and urban) in Uganda.

- The cross-sectional nature of the study precludes any conclusion about the temporal association between IPV and food insecurity.

- Gender-based violence including IPV is a sensitive topic, and may be subject to under-reporting and social desirability bias. Nonetheless, this pre-pandemic assessment serves as an important baseline for further studies of the link between food insecurity and IPV during and after COVID-19-related lockdowns in Uganda.

efforts are needed to prevent and mitigate the expected worsening of this situation as a result of the COVID-19 pandemic.

\section{INTRODUCTION}

Intimate partner violence (IPV) is a major global health problem and human rights violation. IPV consists of intentional and abusive attitudes in the form of physical, sexual and/or emotional offence and controlling behaviours within an intimate partnership. ${ }^{1}$ While IPV can take different forms, maleperpetrated IPV is the most common form of violence against women (VAW). ${ }^{2}$ Globally, one in three ever-partnered women reports experiencing some form of physical and/ or sexual violence in their lifetime, with the 
WHO for the Africa region recording the highest prevalence $(37 \%)$, followed by the Americas $(29.8 \%) .{ }^{3}$ The WHO multicountry study on VAW estimated that the prevalence of male IPV perpetration was $21.1 \%$ for physical violence only, $11.7 \%$ for sexual violence only, and $11.8 \%$ for both physical and sexual violence. ${ }^{4}$ Reports from diverse social and cultural contexts have demonstrated that IPV perpetration begins early in the life course, with most perpetrators reporting that they first engage in it during adolescence. ${ }^{5}$

IPV carries multiple, well-established consequences for women's health and well-being, with femicide being the most extreme form. ${ }^{67}$ IPV is associated with increased risk of sexually transmitted infections (STIs) including $\mathrm{HIV},{ }^{89}$ severe depressive symptoms and substance use and abuse, such as binge drinking. ${ }^{10}$ Furthermore, children born to women experiencing IPV are at higher risk of premature death, poor health outcomes, and emotional and behavioural problems later in life. ${ }^{11}$ Experiencing IPV has been shown to affect women and girls' social and economic empowerment, ${ }^{12}$ including decreased productivity at work, loss of employment opportunities and other important social engagement. ${ }^{13}$

Uganda has one of the highest burdens of IPV in the world and women's experiences of IPV have been the main focus of research on VAW in the country. The 2014 Ugandan Demographic and Health Survey (DHS) found that $47 \%$ of married women had experienced physical IPV in their lifetime, with $29 \%$ reporting lifetime sexual IPV. ${ }^{14}$ Slapping, hitting and beating pregnant women were found to be common, and have been shown to worsen during the course of pregnancy in Northern Uganda. ${ }^{1516}$ Furthermore, the country's HIV incidence has been found to correlate with the frequency and duration of exposure to IPV. ${ }^{17}$

While multiple intersecting factors drive male perpetration of VAW, there is growing evidence linking IPV with food insecurity, most often related to poverty, ${ }^{18} 19$ which is defined as 'a household-level economic and social condition of limited or uncertain access to adequate food' ${ }^{20}$ For example, a cross-sectional study in Kampala slums found that extreme physical violence perpetration and experience of such violence was common among a convenience sample of young men (14-24 years), and was found to correlate with reported hunger and alcohol consumption, illicit drug use, poor mental health status and parental neglect due to alcohol. ${ }^{21}$ In a report from South Africa by Gibbs et al, economic indicators of food insecurity, such as unemployment and low earnings in the past month, were associated with IPV perpetration by men. ${ }^{22} \mathrm{~A}$ small-scale study from Abidjan, Cote d'Ivoire revealed that women with severe forms of food insecurity were at higher risk of experiencing IPV. ${ }^{23}$ While studies from other regions such as Nepal or the USA have established a significant relationship between food insecurity and both IPV perpetration and experiences among women, few studies from sub-Saharan Africa exist on this topic. $^{2425}$
According to the United Nations (UN), food insecurity is increasing in Uganda, rising from $24.1 \%$ in 2006 to $41 \%$ in 2018. ${ }^{26}$ The ongoing COVID-19 crisis has contributed to this considerable increase in Ugandan food insecurity and, in line with predictions of the World Bank and the World Food Programme, is likely to continue to do so. ${ }^{27} 28$ Likewise, there is great concern that IPV is increasing across the world as a consequence of social isolation, poverty and despair due to COVID-19-related lockdowns, social and financial hardships. ${ }^{29}$

Male IPV perpetration against women is a complex, multilevel, social, economic and structural problem, one rooted in unequal gender norms and systems of power. In most cultural settings, a gendered order exists that favours stereotypically masculine men's dominance over women as well as over other more marginalised masculinities that do not live up to the norms of being a 'real' man. ${ }^{30}$ IPV can thus be viewed both as a symptom of and a tool to achieve this type of 'hegemonic' masculinity and power. ${ }^{31}$ Being unable to provide food for one's self or household could be interpreted as failing to meet stereotypical masculine norms, thereby forcing men to use alternative strategies (such as violence) to demonstrate their manhood. ${ }^{19}$ Mental health issues (depression or anxiety), which occur when concerns about food availability are accompanied by poor coping mechanisms such as alcohol consumption, can further lead to IPV as demonstrated by Hatcher et al in periurban South Africa. ${ }^{19}$ Furthermore, the concept of 'patriarchal risk' ${ }^{32}$ can help to theoretically explain the cultural and societal dependence of women on male family members for food and protection, and traditional gender roles are closely linked to all dimensions of food insecurity: access, availability, stability and utilisation. Although women tend to have less control over the household budget, they are often held responsible for feeding the family and blamed if they fail to provide food on the table, leading to different harmful coping strategies such as transactional sex, which in turn increases their risk of HIV. ${ }^{33}$

Given the increasing reports of food insecurity in Uganda $^{26}$ and the lack of existing literature in lowincome and-middle income sub-Saharan African settings, it is important to investigate the potential link between food insecurity and male-perpetrated IPV in the country. The primary aims for the present study were to determine the prevalence of lifetime male IPV perpetration among a representative sample of males in two Ugandan districts, and to assess its association with food insecurity. The secondary aim was to determine whether the strength of the association between food insecurity and male IPV perpetration is affected by sociodemographic factors and health risk behaviours in the urban, semiurban and rural populations under study in central Uganda. The evidence gained through this study can help inform programmes and policies to prevent and better respond to IPV in Uganda and beyond, something that likely will be needed more than ever as we enter into the post-pandemic era. 


\section{METHODS}

\section{Study design}

Data were collected between May 2018 and July 2019 as part of a cross-sectional baseline survey of a longitudinal open population-level cohort established by the Africa Medical and Behavioural Sciences Organization (AMBSO) to conduct population health surveillance (PHS) in the Wakiso and Hoima districts of Uganda. In brief, the AMBSO PHS aims to generate evidence-based data in order to inform policy on the health status of the population through periodic monitoring of disease trends and determinants of health. The cohort includes males and females aged 13-80 years in the study communities and collects yearly data on sociodemographic factors, violence including IPV, non-communicable diseases (diabetes, hypertension, cancers and so on), communicable diseases (such as HIV and STIs), food and nutrition, immunisation of children, health risks (alcohol use, illicit drug consumption, number of sexual partners and male circumcision) and mental health. The current study uses the baseline data with a focus on men's lifetime perpetration of IPV in the study communities.

\section{Study communities}

With a population of nearly 2 million, Wakiso district lies in the central region of Uganda and surrounds parts of the capital, Kampala. Hoima district, located in the Bunyoro Region of midwestern Uganda, has a smaller population of roughly 570000 individuals. The selection of these two districts was purposeful, based on their common and diverse characteristics. Wakiso has a high migrant worker population and is known to be a hot spot for sex workers and men who have sex with men. The discovery of oil in Hoima and increasing mining activities attract migrant workers, sex workers and fisher folks-populations known to have high risk of HIV. ${ }^{34}$ Each district was stratified into urban, semiurban and rural areas. Residents in all urban and semiurban areas, and those in a randomly selected rural community (representing the rural subcounties), were included in the baseline survey.

\section{Study population and sampling}

The study population comprised of males aged 13-80 years in the study communities. A lower age limit of 13 years was considered because of the high prevalence of early sexual debut in Uganda. ${ }^{35}$ This study sample was defined as males who reported ever having a sexual relationship. In each study community, the sampling frame included all households. In each household, all males aged 13-80 years were considered potential participants. Data from the Ugandan population census suggested that the total populations of male inhabitants in Wakiso and Hoima districts were 949035 and 287906, respectively. ${ }^{36}$ In determining the sample size, the study population males aged 13-80 years was estimated to be $65 \%$ of the total male population in each district, that is, 621617 and 188578 in Wakiso and Hoima, respectively. The Ugandan DHS $40 \%$ estimate of male IPV perpetration ${ }^{35}$ and the

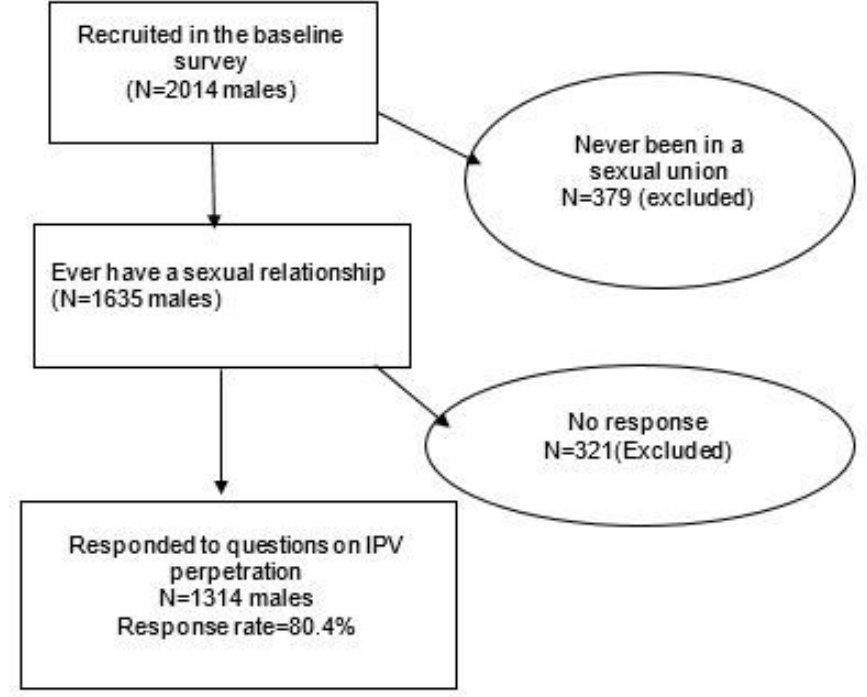

Figure 1 Study flow, illustrating the selection process for inclusion into the analysis. IPV, intimate partner violence.

study population were entered into Epin Info (V.7.2.3.0) STATCalc tool to estimate the study sample. A minimum sample of $\mathrm{N}=738$ was needed to estimate the association between food insecurity and IPV perpetration, with $80 \%$ power at the $\alpha=0.05$ level. To be eligible, participants had to be able and willing to respond to the survey questions and to provide informed consent. The full survey sample consisted of $\mathrm{N}=2014$ male participants who were recruited into the AMBSO PHS cohort. Males who reported not ever having been in a sexual union $(\mathrm{N}=379)$ and those who abstained from responding to questions on male IPV perpetration $(\mathrm{N}=321)$ were excluded (figure 1$)$.

Even though the individual response rate was $80.4 \%$, the final analysis sample $(\mathrm{N}=1314)$ was near double the estimated sample of $\mathrm{N}=738$ participants needed to estimate the association. This $80.4 \%$ response rate is similar to that of a multicountry survey on male IPV perpetration in Asia. ${ }^{4}$ A sensitivity analysis comparing the characteristics of those who responded to the IPV questions and those who did not respond is included in online supplemental appendix 1 . The sensitivity analysis revealed that, in comparison with those who responded to the IPV questions, non-respondents were more likely to be young, Christian and of lower educational level. There was no significant difference in food insecurity among nonrespondents and respondents. Any observed differences did not affect the findings as the final sample was more than double the minimum estimated sample needed to establish an association.

\section{Procedures}

Data were collected in the baseline using a structured questionnaire covering 10 domains: sociodemographics; first sex experience; family planning practice; marital status and practices; food supply and food security; IPV; HIV testing services; HIV care and treatment services; prostate cancer and behaviour risk. Trained data collectors of the same sex as participants collected the data via 


\begin{tabular}{|c|c|}
\hline $\begin{array}{l}\text { Type of violence } \\
\text { perpetration }\end{array}$ & $\begin{array}{l}\text { Have you ever done any of the } \\
\text { following to your sexual partner? }\end{array}$ \\
\hline $\begin{array}{l}\text { Physical violence } \\
\text { only ('yes' to } \geq 1 \\
\text { indicator) }\end{array}$ & $\begin{array}{l}\text { Push, slap or hold partner down? } \\
\text { Punch with fist or with something } \\
\text { that could hurt partner? } \\
\text { Kick or drag partner? } \\
\text { Tried to strangle or burn partner? } \\
\text { Attacked partner with a knife, gun or } \\
\text { other types of weapon? }\end{array}$ \\
\hline $\begin{array}{l}\text { Sexual violence } \\
\text { only ('yes' to } \geq 1 \\
\text { indicator) }\end{array}$ & $\begin{array}{l}\text { Force her to perform sexual acts } \\
\text { against partner's will? } \\
\text { Used threats to force her to have sex } \\
\text { when she did not want to? } \\
\text { Physically force her to have sex } \\
\text { against her wish? }\end{array}$ \\
\hline $\begin{array}{l}\text { Physical and } \\
\text { sexual violence } \\
\text { ('yes' to } \geq 1 \\
\text { indicators of both) }\end{array}$ & $\begin{array}{l}\text { Perpetration of both physical } \\
\text { violence and sexual violence }\end{array}$ \\
\hline $\begin{array}{l}\text { No IPV } \\
\text { perpetration }\end{array}$ & $\begin{array}{l}\text { No perpetration of both physical } \\
\text { violence and sexual violence }\end{array}$ \\
\hline
\end{tabular}

$\mathrm{IPV}$, intimate partner violence.

face-to-face interviews, using tools translated into local languages (Luganda in Wakiso and Runyoro in Hoima).

In addition to these survey questions, the PHS collected $10 \mathrm{~mL}$ of venous blood samples that were used to determine the HIV and syphilis status of participants, and aliquots stored for other future studies. HIV status was determined following the Ugandan Ministry of Health rapid test algorithm, ${ }^{37}$ and the rapid plasma regain serological test was used to determine syphilis status of the participants.

\section{Dependent variables}

The dependent variable was adapted from the WHO multicountry study on VAW, ${ }^{3}$ and defined as lifetime selfreported perpetration of physical and/or sexual violence against an intimate (sexual) partner. Following the approach used by Fulu $e t a l,{ }^{4}$ the outcome was grouped into four independent and unordered categories: (1) no perpetration of physical and/or sexual violence (no IPV); (2) physical IPV perpetration only; (3) sexual IPV perpetration only; and (4) both physical and sexual IPV perpetration (table 1). The 'no IPV perpetration' category was used as the reference group, referring to males reporting to never have perpetrated physical and/or sexual violence against their intimate sexual partner. The 'physical violence only' category consisted of males reporting to have perpetrated one or more forms of physical violence, but who had never used any sexual violence; 'sexual violence only' was coded using the same approach but referring to one or more forms of sexual violence. Males who reported to having perpetrated both physical and sexual violence in their lifetime were grouped into the 'physical and sexual violence' category. Lifetime estimates were used in this study in order to capture all selfreports of IPV perpetration.

\section{Independent variables}

Food insecurity

The main independent variable was past-year food insecurity, assessed using an adapted version of the Food Insecurity Experience Scale questions ${ }^{38}$ in which six selected items were used to evaluate the household food situation during the preceding 12 months (table 2).

In line with international definitions, ${ }^{39}$ negative responses to assessment questions such as 'no' 'never' 'only 1 or 2 months' were coded as ' 0 ' (referring to those who reported having minor access problems for food during the preceding 12 months), while positive or affirmative responses such as 'yes', 'always', 'almost every month', 'some months but not every month' were coded as ' 1 ' (referring to having problems with access to adequate food during the preceding 12 months). All codes were summed to obtain a total score of up to 6 (ie, 0-6) for food insecurity, with higher scores indicating the extent of food insecurity. As adapted from international approaches ${ }^{39}$ participants were categorised into the following categories: no food insecurity $(0-1)$, low food insecurity (2-4) and high food insecurity (hunger) (5-6). Due to the small proportion reporting high food insecurity $(3.6 \%)$, low food insecurity and high food insecurity were merged during the modelling procedures in line with previous studies, ${ }^{19}$ that is, comparing food insecurity against food security in line with previous studies.

\section{Sociodemographic and health risk behaviours}

Other important independent variables included sociodemographic indicators such as: study district (urban/ semiurban/rural); age; education level (categorised into primary school and below, secondary school and post-secondary); marital status (married or in a union/ not married); religion (categorised into Christian, nonChristians); and having living children (yes/no). Health risk behaviours included: number of lifetime sexual partners (one partner/two or more partners); pastyear condom use (yes/no); use of illicit drugs (yes/no); alcohol consumption (yes/ no) and male circumcision (yes/no). The choice of health risk behaviours was based on previous studies indicating number of sexual partners as well as (low) condom use ${ }^{40-42}$ and male circumcision ${ }^{42}$ as risk factors for IPV.

\section{Statistical analysis}

We first conducted descriptive analyses to explore the distribution of variables and to identify outliers. The analysis in this report was not weighted. Missing values for covariates were replaced using multiple imputation assuming random missingness. Pearson's $\mathrm{X}^{2}$ test and Fisher's exact test were used to compare proportions with $\alpha$ set at 5\%. Next, we performed bivariate multinomial logistic regression to determine the crude relative risk 
Table 2 Assessment questions and coding for the measurement and classification of food insecurity among participants in the study

\begin{tabular}{|c|c|c|}
\hline Question & Responses & Coding of responses \\
\hline $\begin{array}{l}\text { Q.1 In the past } 12 \text { months, were there months in which } \\
\text { you did not have enough food to meet your family's } \\
\text { needs? }\end{array}$ & Yes/no & Yes $=1$, no $=0$ \\
\hline $\begin{array}{l}\text { Q.2 In the last } 12 \text { months, have you or other adults in } \\
\text { your household withheld a meal because there was not } \\
\text { enough food? }\end{array}$ & Yes/no & Yes $=1$, no $=0$ \\
\hline $\begin{array}{l}\text { Q.4 In the last } 12 \text { months, did you ever cut the size } \\
\text { of any of the children's meals because there wasn't } \\
\text { enough food? }\end{array}$ & Yes/no & Yes $=1$, no $=0$ \\
\hline $\begin{array}{l}\text { Q.5 In the last } 12 \text { months, how often were you worried } \\
\text { that food would run out? }\end{array}$ & Always/sometimes/never & Always $=1$, sometimes $=1$, never $=0$ \\
\hline
\end{tabular}

Source: Food Insecurity Experience Scale.

ratios (RRRs) and 95\% CIs of IPV perpetration in relation to the independent variables. We followed the approach used by Fulu et at and used 'No IPV perpetration' as the base outcome against which all other outcomes were compared, assuming that the association of food insecurity is different for each typology of violence. This type of regression produces RRRs, which are the exponentiated coefficients of the regression, and explain the relative effect of the independent variable on the outcomes using one of the outcomes as a base outcome. A full model was built to explain the associated factors to IPV perpetration in relation to both food insecurity, health risk behaviours and sociodemographic background. The full model (adjusting for food insecurity and sociodemographic and health risk behaviours) included all the variables from the bivariate analysis, irrespective of significance levels, that are theoretically known to be associated with IPV perpetration. Variables for the final adjusted model were selected through backward elimination using a maximum likelihood ratio test. All analyses were conducted using STATA V.16 (StataCorp), while Microsoft Office Excel was used to design figures.

\section{Patient and public involvement}

The study team worked hand in hand with community health workers, local community leaders and a communityresearch advisory structure to develop and clarify a common understanding of the aims of the populationbased survey, the design and operational aspects as well as how results will be disseminated. As part of this 'patient and public involvement' effort, a consensus was reached with the advisory committee on a plan to increase general public awareness of the study and health issues that were deemed areas of PHS focus.

\section{RESULTS \\ Sample characteristics}

Table 3 shows the characteristics of the study participants. The mean age of respondents was 34 years (SD: \pm 12.9 ). Food insecurity was found to affect one in four men, with $20.7 \%$ and $3.6 \%$ categorised as low versus high food insecurity, respectively. About one-third and $50 \%$ of men reported having had multiple sex partners and used alcohol in the past year, respectively; and approximately $6 \%$ tested positive for HIV.

\section{Prevalence of lifetime IPV perpetration}

Table 4 presents the prevalence of perpetration of different forms of IPV against an intimate (sexual) partner by male participants. Most $(73.6 \%)$ males reported never having perpetrated any form of IPV. The prevalence of self-reported physical IPV perpetration ranged from $19.3 \%$ (pushing, slapping, holding down) to $0.9 \%$ (attacked partner with a knife, gun or other weapon), with $14.6 \%$ having perpetrated any form of physical violence only. Lifetime perpetration of sexual IPV ranged from $8.2 \%$ (threatened or pressured partner into sex when unwanted) to $5.4 \%$ (physically forced partner to have sex) and $2.4 \%$ (used other types of force to have sex), with $6.5 \%$ of males reporting having perpetrated any form of sexual IPV only. In total, $5.3 \%$ of males reported previous perpetration of both physical and sexual IPV. 
Table 3 Sample characteristics of male respondents in the two study districts in Uganda ( $N=1314)$

\begin{tabular}{lll}
\hline Variable & $\mathbf{n}$ & $\%$ \\
\hline $\begin{array}{l}\text { Age (mean, SD) } \\
\text { Education }\end{array}$ & $34 \pm 12.9$ & \\
$\quad$ Primary and below & 688 & 52.4 \\
$\quad$ Secondary school & 477 & 36.3 \\
$\quad \begin{array}{l}\text { Post-secondary } \\
\text { Marital status }\end{array}$ & 149 & 11.3 \\
$\quad$ Married or in a union & 1163 & 88.5 \\
$\quad$ Not married & 151 & 11.5 \\
Have any living children & & \\
$\quad$ Yes & 999 & 76.2 \\
$\quad$ No & 312 & 23.8 \\
\hline
\end{tabular}

Religion

\begin{tabular}{|c|c|c|}
\hline Christianity & 1068 & 81.3 \\
\hline Non-Christian & 246 & 18.7 \\
\hline \multicolumn{3}{|l|}{ Past-year food security } \\
\hline No food insecurity & 995 & 75.7 \\
\hline Low food insecurity & 272 & 20.7 \\
\hline High food insecurity & 47 & 3.6 \\
\hline Score (mean, SD) & $1.48 \pm 1.05$ & \\
\hline \multicolumn{3}{|c|}{ Number of lifetime sexual partners } \\
\hline One partner & 919 & 69.9 \\
\hline Two or more partners & 395 & 30.1 \\
\hline \multicolumn{3}{|l|}{ Current use of condoms } \\
\hline Yes & 519 & 39.5 \\
\hline No & 795 & 60.5 \\
\hline \multicolumn{3}{|c|}{ HIV status from blood sample } \\
\hline Negative & 1224 & 94.3 \\
\hline Positive & 74 & 5.7 \\
\hline \multicolumn{3}{|l|}{ Past-year alcohol use } \\
\hline Yes & 677 & 48.5 \\
\hline No & 640 & 51.5 \\
\hline \multicolumn{3}{|l|}{ Circumcised } \\
\hline Yes & 659 & 50.2 \\
\hline No & 655 & 49.8 \\
\hline \multicolumn{3}{|c|}{ Past-year use of illicit drugs } \\
\hline Yes & 43 & 3.3 \\
\hline No & 1271 & 96.7 \\
\hline
\end{tabular}

Figure 2 shows the prevalence of self-reported IPV perpetration across different age groups. As can be seen, the prevalence of physical violence only and both physical and sexual violence was highest among those aged 25-34years old compared with the other age groups $(\mathrm{p}<0.001)$, with perpetration of sexual violence only being most commonly reported by young men (18-24 years $)$ and less common after age 34 years $(\mathrm{p}=0.517)$.
Table 4 Prevalence of self-reported lifetime perpetration of IPV against a sexual partner among ever-partnered males aged 13-80 years in two districts of Uganda, May 2018-July 2019

\begin{tabular}{|c|c|c|}
\hline & \multicolumn{2}{|c|}{$\begin{array}{l}\text { Lifetime IPV } \\
\text { perpetration } \\
(\mathrm{N}=1314)\end{array}$} \\
\hline & $\mathbf{n}$ & $\%$ \\
\hline Physical violence (any form) & 261 & 19.9 \\
\hline Push, slapped or held down partner & 253 & 19.3 \\
\hline Kicked or dragged partner & 54 & 4.1 \\
\hline Tried to strangle partner & 19 & 1.5 \\
\hline $\begin{array}{l}\text { Attacked partner with a knife, gun or } \\
\text { other weapon }\end{array}$ & 12 & 0.9 \\
\hline $\begin{array}{l}\text { Punch with fist or with something } \\
\text { that could hurt partner }\end{array}$ & 61 & 4.6 \\
\hline Sexual violence (any form) & 155 & 11.8 \\
\hline $\begin{array}{l}\text { Threatened or pressured partner into } \\
\text { sex when unwanted }\end{array}$ & 108 & 8.2 \\
\hline Physically forced partner into sex & 70 & 5.4 \\
\hline $\begin{array}{l}\text { Used other ways to force partner to } \\
\text { perform sexual acts when unwanted }\end{array}$ & 31 & 2.4 \\
\hline Any physical or sexual violence & 347 & 26.4 \\
\hline Physical IPV perpetration only & 192 & 14.6 \\
\hline Sexual IPV perpetration only & 86 & 6.5 \\
\hline $\begin{array}{l}\text { Both physical and sexual IPV } \\
\text { perpetration }\end{array}$ & 69 & 5.3 \\
\hline No IPV perpetration & 967 & 73.6 \\
\hline
\end{tabular}

IPV, intimate partner violence.

\section{Factors associated with IPV perpetration \\ Bivariate analysis}

In bivariate analysis, food-insecure participants had an RRR of 2.71 (95\% CI 1.64 to 4.46) to have perpetrated both physical and sexual violence, but no significantly higher risk to have perpetrated physical versus sexual violence only, respectively (table 5). Compared with the youngest age group 13-24 years, young adult participants (25-34 years) had an RRR of 2.59 (95\% CI 1.64 to 4.07) for perpetrating physical violence only, and 2.64 (95\% CI 1.30 to 5.36) for both physical and sexual violence, and the RRR for those aged $35+$ years was 2.16 (95\% CI 1.38 to 3.38) for physical violence. Being married was associated with a lower relative risk of having perpetrated sexual violence only. Having living children and reporting no condom use were associated with perpetration of physical violence only. Reported use of illicit drugs during the preceding year was associated with perpetration of physical violence only and both physical and sexual violence. There was no association between education level with IPV perpetration.

Multivariable analysis

Table 6 illustrates the adjusted RRR (aRRR) for IPV perpetration in relation to food insecurity, controlling 


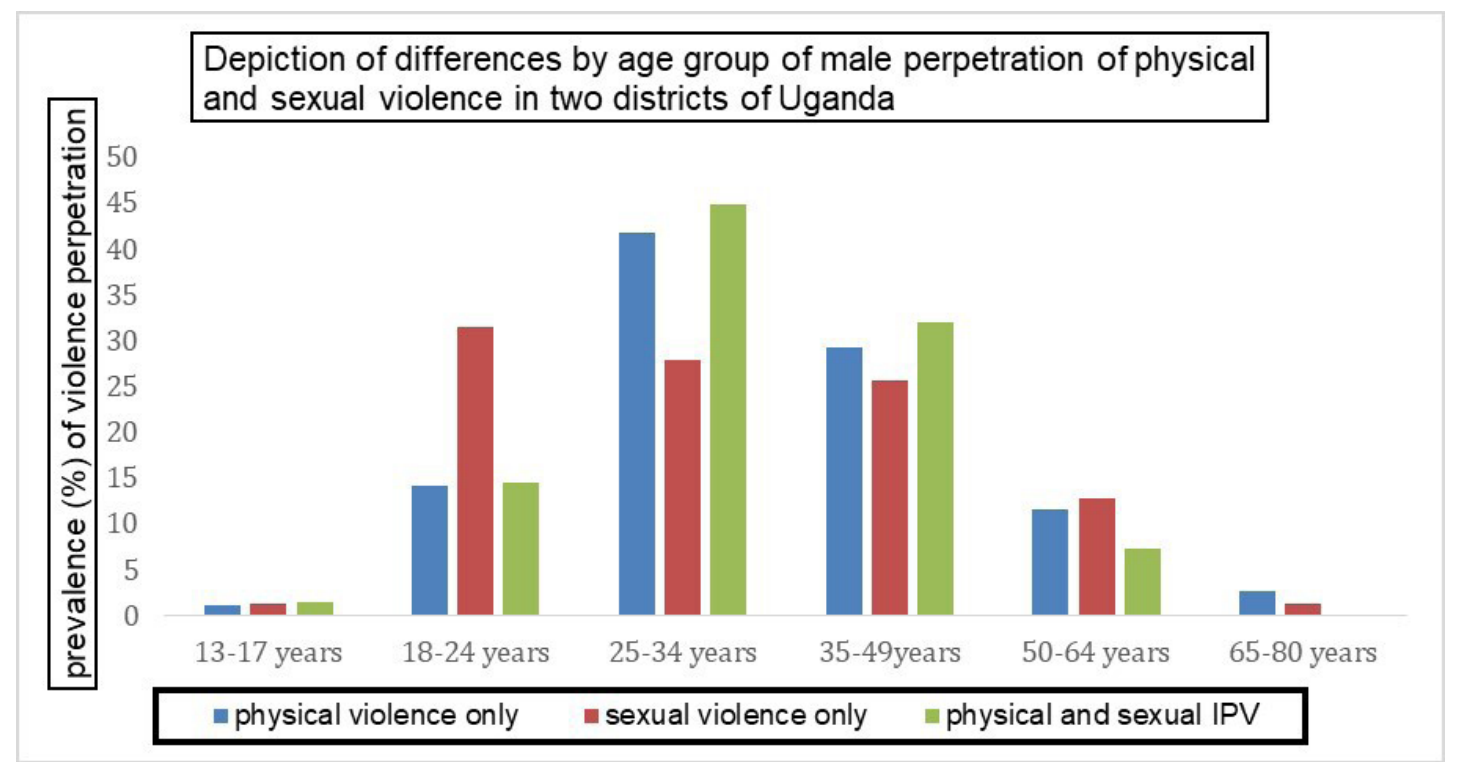

Figure 2 Depiction of lifetime prevalence by age group of male lifetime IPV perpetration in two districts of Uganda, May 2018July 2019. IPV, intimate partner violence.

for sociodemographic factors and health risk behaviours. Food insecurity remained significantly associated with self-reported perpetration of both physical and sexual violence $(\mathrm{aRRR}=2.57,95 \%$ CI 1.52 to 4.32$)$. In terms of independent health risk factors, having two or more lifetime sexual partners also remained associated with perpetration of physical violence only, and both physical and sexual violence. Any alcohol consumption remained associated with all typologies of IPV perpetration under study, and illicit drug use remained associated with physical violence and both physical and sexual violence. In terms of sociodemographics, having living children remained associated with perpetration of physical violence only, while being married appeared to be protective against perpetration of sexual violence only. Age and religion were not associated with any IPV perpetration in the adjusted model.

\section{DISCUSSION}

The current study set out to explore the prevalence of lifetime male IPV perpetration and its association with food insecurity as well as sociodemographics and health risk behaviours in two Ugandan districts. We found that one in four men reported ever perpetrating any form of physical and/or sexual violence against their intimate partners, and 5.3\% reported perpetrating both physical and sexual IPV. Past-year food insecurity was associated with male perpetration of both physical and sexual violence after adjusting for age group, religion, number of lifetime sexual partners, marital status, having living children, alcohol use and illicit drug use.

The prevalence of lifetime perpetration of IPV reported by this study is lower than that of other studies conducted in the region. ${ }^{19} 4344$ Obtaining accurate data on the true burden of VAW is a global concern due to under-reporting. ${ }^{45}$ It is likely that community awareness about laws and litigations in place to prevent VAW may undermine truthful responses to IPV survey questions. Nonetheless, a fair proportion of men in our survey did admit to IPV perpetration. In these new demographic surveillance sites and first round of the assessments, it is possible that the communities have not yet built sufficient trust with the survey teams to report very sensitive information and potential illegal behaviours. Comparing the prevalence estimates of this study with data from previous studies is therefore difficult, mainly due to the existence of limited research in a sub-Saharan African context, and the non-standardised ways in which surveys have assessed male IPV perpetration. For instance, although the 2006 Ugandan DHS ${ }^{14}$ found that $40 \%$ of males perpetrated IPV, this finding was solely based on reports of physical violence (eg, partner hitting, slapping and kicking) without taking into account sexual IPV perpetration. Another large-scale study that focused on past-year perpetration (rather than lifetime) in the Rakai district of Uganda indicated a prevalence of $10.4 \%$ for physical violence and $3.1 \%$ for sexual violence. ${ }^{42}$ In the present study, $19.3 \%$ of men reported ever slapping or pushing their intimate partners, an estimate that is similar to other countries including Ghana $(17.4 \%)^{43}$ and Vietnam $(23.5 \%),{ }^{46}$ but lower than those obtained by the International Men and Gender Equality Study in the Democratic Republic of Congo (45.1\%) and Rwanda (39.1\%). ${ }^{44}$

In this pre-pandemic assessment, one in four men reported to be food insecure, and food insecurity was associated with almost three times the relative risk of having perpetrated both physical and sexual IPV. Our findings are consistent with results of a recent study from a periurban setting of South Africa, in which food insecurity doubled the odds of males' perpetration of IPV. ${ }^{19}$ The 


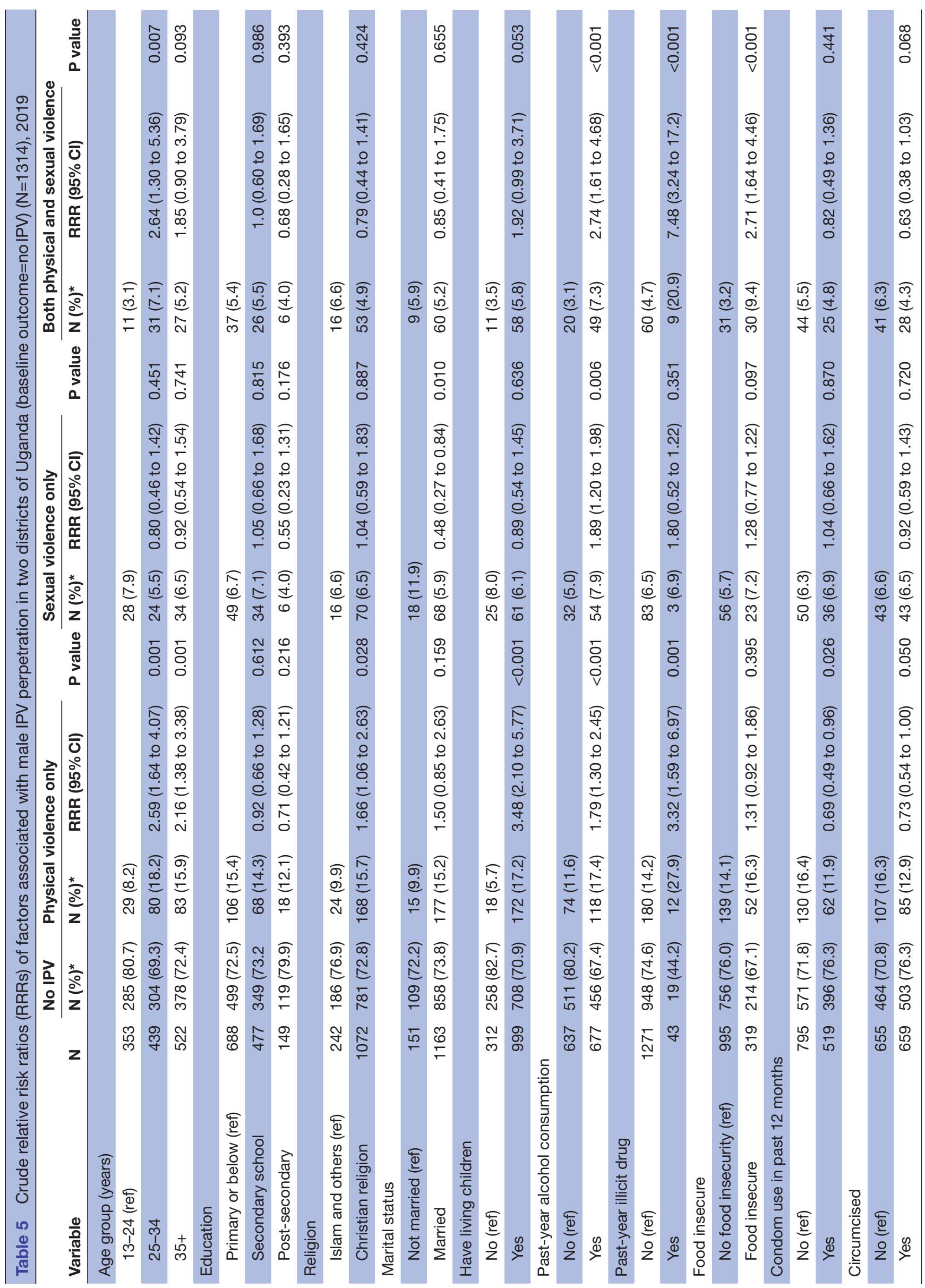


results from our study align with findings from $\mathrm{Nepal}^{25}$ and the $\mathrm{USA}^{24}$ that food insecurity was more common among married women who had experienced physical violence from their intimate sexual partners; however, the causal relationships are uncertain. The World Food Programme expects the number of people who are food insecure to increase dramatically as a consequence of COVID-19-related mobility restrictions and poverty, potentially driving another 135 million people worldwide onto the brink of starvation. Similarly, the UN Population Fund warns of increases in IPV as a consequence of social isolation, hopelessness and financial hardship. ${ }^{29}$ Thus, the pre-pandemic estimates presented in this study are expected to worsen and should serve as an important warning indicator for urgent mitigation efforts.

Previous research indicates that the association between food insecurity and IPV perpetration may be driven by mental health problems such as anxiety and depression that arise from concerns about food availability related to poverty and unemployment, ${ }^{19}$ which are also expected to increase as a result of the current pandemic. The influence of conservative gender norms is important, whereby the inability of men to provide for their partners and households affects their perceived masculinity and contributes to their use of violence. ${ }^{47} \mathrm{~A}$ qualitative study in Bangladesh found that inadequate food portions offered to men may trigger retaliatory acts of violence against their wives, and that men could withhold resources used to acquire food as a form of power. ${ }^{48}$ Corroborated by previous research, the present study also found that men who had consumed alcohol in the past year and who have multiple lifetime sexual partners were at significantly higher risk of perpetrating IPV. ${ }^{49} 50$ The use of illicit drugs, though assumed to be under-reported, was also found to be associated with IPV perpetration after adjusting for confounding, in line with previous research. ${ }^{51}$ The association between food insecurity and IPV perpetration may thus be influenced and mediated by multiple factors previously examined, for example, through structural equation models including poor mental health, gender attitudes, multiple partnerships, controlling behaviours and alcohol consumption. ${ }^{192}$

Furthermore, we found that the prevalence of IPV perpetration varied by age group, with reports of sexual and physical IPV being more common among young adult males compared with older men, while in the adjusted models, being 35 years and older appears to confer a protective effect against perpetraton of IPV. These findings are in line with previous studies from the USA. ${ }^{50} 52$ For young men, it is possible that a relative lack of relationship experiences, masculine-identity seeking and vulnerability to peer influence ${ }^{50} 52$ increase their tendency to perpetrate violence. ${ }^{53}$ These findings have implications for the design of future preventive interventions for different subpopulations, especially men in the younger age groups.

Our findings highlight the need for early prevention of IPV that targets young men, and the necessity 


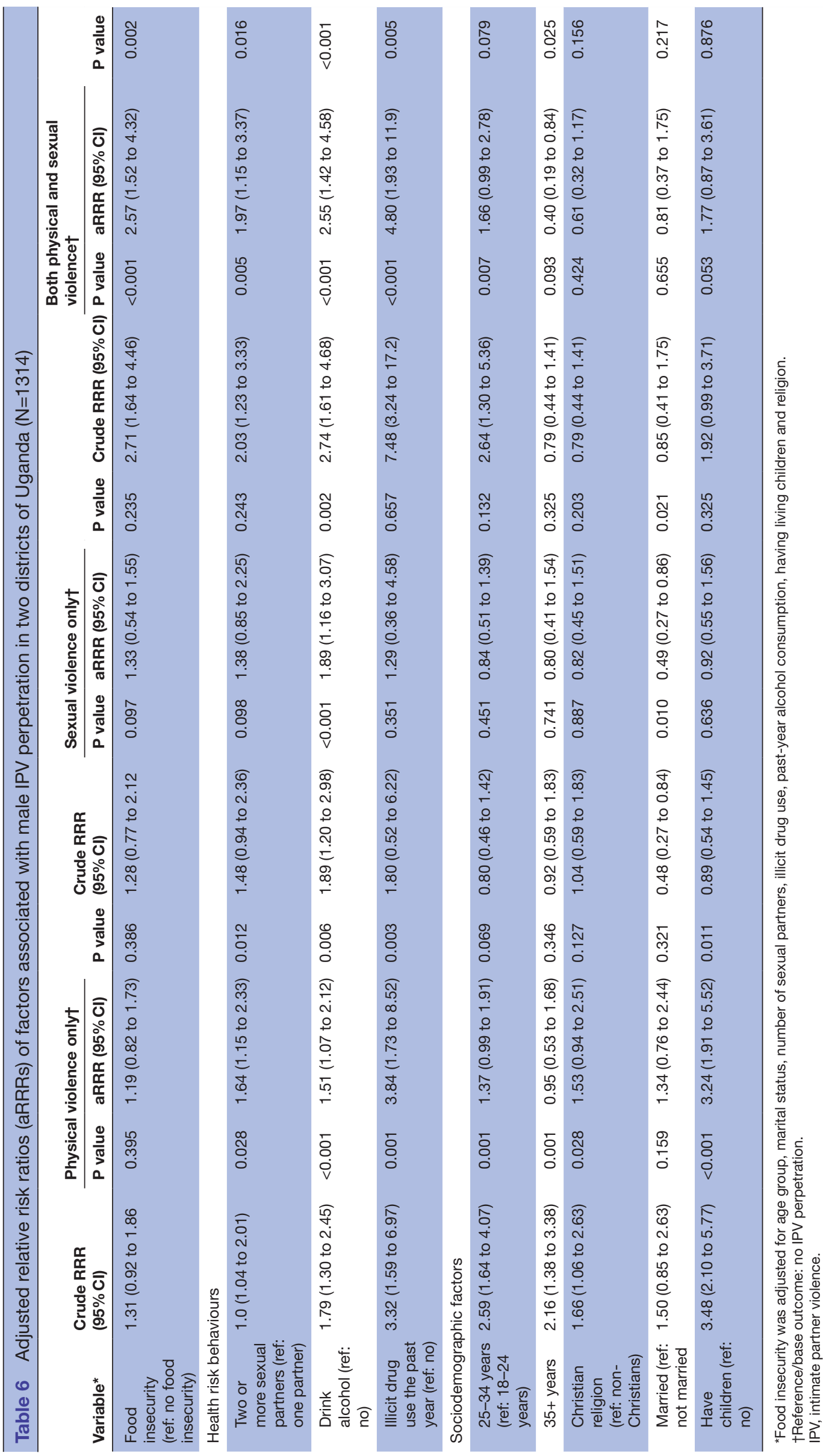


to investigate and respond to food insecurity within the framework of IPV prevention. Even though a temporal association between IPV and food insecurity is yet to be established, the findings of this study should serve as an alert to more initiatives to address IPV, particularly in light of an expected dramatic increase in both IPV and food insecurity reports as a consequence of the COVID-19 pandemic. ${ }^{29}$ Existing IPV preventive interventions in Uganda such as the SASA community-based programme $^{54}$ and the Program P initiative ${ }^{55}$ may provide concrete guidelines for efforts to engage more men in IPV preventive programmes. The SASA and Program P interventions also use comprehensive strategies (including HIV risk reduction) and should be strengthened with considerations for advocacy to include for food security measures as part of the packages to respond to IPV. There is an urgent need to adapt context-relevant interventions to address food insecurity, especially during the current pandemic with severe increases in both IPV and food insecurity warning and reports worldwide. This is of particular importance in sub-Saharan Africa, where a huge surge in poverty rates and food insecurity is expected. ${ }^{56}{ }^{57}$ Thus, our study suggests that IPV may become an even larger public health issue in Uganda and beyond in the near future. Potential interventions to reduce poverty and food insecurity could include: efforts to boost agricultural food production such as short-term provision of seeds and tools to rehabilitate farming and facilitate the acquisition of credits for small businesses; conditional cash transfers to women household heads to enable purchase of necessities and pay for health expenses; implementation of school fee waivers and school feeding programmes; and the provision of food vouchers to enable purchase of food in local markets and the emergency distribution of food. ${ }^{58}$ Structural interventions to address IPV should be advocated for, including more discussion on gender norms and harmful masculinities in schools and communities, putting in place systems to prevent male violence perpetration, encouraging women to report incidences of IPV accompanied with a strengthening of legislation, training and monitoring of the police force and justice departments in IPV-related issues and set up support and counselling centres for women who experience IPV. ${ }^{59}$

\section{LIMITATIONS}

This study is one of the first to investigate lifetime perpetration of different forms of physical and sexual violence among both younger and older men, and to examine their association with food insecurity and male IPV perpetration in a population-based, representative cohort in rural, urban and semiurban Uganda. Given the self-reported nature of the data on a sensitive topic like IPV, underreporting of physical and sexual IPV as well as recall bias is possible. Some participants may have considered the questions to be too private and/or shameful to talk about, and some may have feared legal implications (given that IPV is illegal), or found it challenging to respond honestly.
In light of this potential social desirability bias, the true rate of IPV perpetration is likely higher than reported in this first round of the assessments. In the future, exposure to and increased population trust in the data collectors in this reoccurring population-based survey may further improve the confidence in self-reporting IPV perpetration. Even though the minimum sample needed for this study was attained, a fairly high proportion of men did not respond to the IPV questions in the survey. The sensitivity analysis revealed, however, that this had no significant effect on the findings. Data on poverty indicators such as income levels and employment status were unfortunately lacking at individual level, but it can be assumed that food insecurity is a reflection of income level and the availability and access to livelihood resources. Finally, due to the cross-sectional nature of the data coupled with the measurement of food insecurity as past year and IPV as lifetime, we were unable to establish a temporal association between food insecurity and IPV perpetration. Even though multivariate analysis was performed in this study, the likelihood of residual confounding still remains.

\section{CONCLUSIONS}

Although likely an underestimation, the reported prevalence of male IPV perpetration in these Ugandan communities was still sizeable-in particular among young men, and must be addressed by enhanced IPV preventive strategies and programming in schools and communities. Food insecurity was associated with both physical and sexual IPV, suggesting the need for integrated approaches to address VAW, poverty and food insecurity. Considering the impact of COVID-19 lockdowns and multiple reports on increased IPV, as well as expected huge increases in poverty rates and food insecurity throughout Uganda, the need for preventive interventions is even greater than before. Longitudinal surveys are needed to investigate the temporal relationships and drivers of food insecurity in Uganda and beyond, and to determine its impact on different forms of violence.

Twitter George Awungafac @awungafacg

Acknowledgements We thank the staff of Africa Medical and Behavioral Sciences Organization (AMBSO); the PHS study participants; the local community leadership; and the Wakiso and Hoima Districts Directorates of Health services for supporting this work.

Contributors The original ideas leading to the population health surveillance study, from which this manuscript is derived, were put together by SM, FN, GK, GN, SW and AME. GA and AK conceptualised the research questions for the current study. GA analysed the data, wrote the first draft of the study and oversaw the manuscript development process. SM, FN, SW and GK coordinated the participant recruitment as well as the data collection, management and entry. RBM, LZ, GN, GKN, EK and $\mathrm{JN}$ participated in actual data collection from the study participants. CFS and SR contributed to describing the measurement and classification of food insecurity. AK provided oversight to the study, providing edits, structure and scope to the study together with AME. All authors reviewed the drafts leading to this final manuscript.

Funding This study was made possible by private funds from AMBSO directors, the Karolinska Institute through a Swedish Research Council grant (grant number: 2019-04474), and the Swedish Institute which supported the first author with an educational study grant (ref: 02205/2019). 
Competing interests None declared.

Patient consent for publication Not required.

Ethics approval The AMBSO PHS cohort study received ethical approval from the Clarke International University Ethics Committee (ref: CIUREC/0059) as the local Institutional Review Board (IRB) of record, and clearance from the Ugandan Council of Science and Technology (ref: SS4468). Clearance was obtained from both districts to conduct the study. All participants provided a written informed consent/ assent before participating in the study. With the exception of emancipated minors (under 18 years) who (like adults) gave their own written or oral assent in addition to written parental/guardian consent was obtained. Data were collected by a study team trained and certified in human subject protection and Good Clinical Practice. Interviews were conducted in private. Unique identification codes were used in all computerised data, and the lists that linked participants' names to the codes were accessible only to senior project staffs in password-protected computers. Participants who tested positive for HIV infection and syphilis were linked to specialised care while those who needed other health support services were referred to health facilities of their choice.

\section{Provenance and peer review Not commissioned; externally peer reviewed.}

Data availability statement Data are available upon reasonable request. The data for this study are strictly not available to the public. A reasonable request for the data can be done by contacting SM (smugamba@gmail.com).

Supplemental material This content has been supplied by the author(s). It has not been vetted by BMJ Publishing Group Limited (BMJ) and may not have been peer-reviewed. Any opinions or recommendations discussed are solely those of the author(s) and are not endorsed by BMJ. BMJ disclaims all liability and responsibility arising from any reliance placed on the content. Where the content includes any translated material, BMJ does not warrant the accuracy and reliability of the translations (including but not limited to local regulations, clinical guidelines, terminology, drug names and drug dosages), and is not responsible for any error and/or omissions arising from translation and adaptation or otherwise.

Open access This is an open access article distributed in accordance with the Creative Commons Attribution 4.0 Unported (CC BY 4.0) license, which permits others to copy, redistribute, remix, transform and build upon this work for any purpose, provided the original work is properly cited, a link to the licence is given, and indication of whether changes were made. See: https://creativecommons.org/ licenses/by/4.0/.

\section{ORCID iDs}

George Awungafac http://orcid.org/0000-0002-5859-0336

Carl Fredrik Sjöland http://orcid.org/0000-0003-3594-8849

\section{REFERENCES}

1 Krug EG, Mercy JA, Dahlberg LL, et al. The world report on violence and health. Lancet 2002;360:1083-8.

2 Richardson JR, Feder G, Coid J. Domestic violence affects women more than men. BMJ 2002;325:779.

3 World Health Organisation. Global and regional estimates of violence against women: prevalence and health effects of intimate partner violence and non-partner sexual violence. Geneva, 2013.

4 Fulu E, Jewkes R, Roselli T, et al. Prevalence of and factors associated with male perpetration of intimate partner violence: findings from the un Multi-country cross-sectional study on men and violence in Asia and the Pacific. Lancet Glob Health 2013;1:e187-207.

5 Peitzmeier SM, Kågesten A, Acharya R, et al. Intimate partner violence Perpetration among adolescent males in disadvantaged neighborhoods globally. J Adolesc Health 2016;59:696-702.

6 Martin PM, Carvajal N. Feminicide as 'act' and 'process': a geography of gendered violence in Oaxaca. Gender, Place \& Culture 2016;23:989-1002.

7 Prieto-Carrón M, Thomson M, Macdonald M. No more killings! women respond to femicides in central America. Gender Develop 2007:15:25-40.

8 Campbell JC, Baty ML, Ghandour RM, et al. The intersection of intimate partner violence against women and HIV/AIDS: a review. Int J Inj Contr Saf Promot 2008;15:221-31.

9 Coker AL. Does physical intimate partner violence affect sexual health?: a systematic review. Vol. 8, trauma, violence, and abuse. Los Angeles, CA: Sage Publications, 2007: 149-77.

10 Tsai AC, Wolfe WR, Kumbakumba E, et al. Prospective study of the mental health consequences of sexual violence among women living with HIV in rural Uganda. J Interpers Violence 2016;31:1531-53.
11 Hossain MA, Sumi NS, Haque ME, et al. Consequences of intimate partner violence against women on under-five child mortality in Bangladesh. J Interpers Violence 2014;29:1402-17.

12 The World Bank. The cost of violence. Washington, DC, 2009.

13 López-Sánchez MJ, Belso-Martínez JA, Hervás-Oliver JL. A review of economic consequences and costs of male violence against women. Indian J Gend Stud 2019;26:424-34.

14 Ogland EG, Xu X, Bartkowski JP, et al. Intimate partner violence against married women in Uganda. J Fam Violence 2014;29:869-79.

15 Clarke S, Richmond R, Black E, et al. Intimate partner violence in pregnancy : sectional study from post- conflict a cross- northern Uganda 2019:1-9.

16 Kaye DK, Mirembe FM, Bantebya G, et al. Domestic violence during pregnancy and risk of low birthweight and maternal complications: a prospective cohort study at. Uganda: Mulago Hospital.

17 Kouyoumdjian FG, Calzavara LM, Bondy SJ, et al. Intimate partner violence is associated with incident HIV infection in women in Uganda. AIDS 2013;27:1331-8.

18 Food and Agricultural Organisation of the United Nation. How can food security interventions contribute to reducing gender-based violence? Issue Brief, 2017.

19 Hatcher AM, Stöckl H, McBride R-S, et al. Pathways from food insecurity to intimate partner violence Perpetration among PeriUrban men in South Africa. Am J Prev Med 2019;56:765-72.

20 Food insecurity: a public health issue. Public Health Rep 2016;131:655

21 Swahn MH, Gressard L, Palmier JB, et al. Serious violence victimization and perpetration among youth living in the slums of Kampala, Uganda. West J Emerg Med 2012;13:253-9.

22 Gibbs A, Jewkes R, Willan S. Associations between poverty, mental health and substance use, gender power, and intimate partner violence amongst young (18-30) women and men in urban informal settlements in South Africa : A cross-sectional study and structural equation model 2018:1-19.

23 Fong S, Gupta J, Kpebo D, et al. Food insecurity associated with intimate partner violence among women in Abidjan, Cote d'Ivoire. Int J Gynaecol Obstet 2016;134:341-2.

24 Ricks JL, Cochran SD, Arah OA, et al. Food insecurity and intimate partner violence against women: results from the California women's health survey. Public Health Nutr 2016;19:914-23.

25 Diamond-Smith N, Conroy AA, Tsai AC, et al. Food insecurity and intimate partner violence among married women in Nepal. J Glob Health 2019;9:010412.

26 Uganda's food insecurity worsens - UN report [online]. Available: https://www.independent.co.ug/ugandas-food-insecurity-worsensun-report/ [Accessed 30 Apr 2020].

27 World Food Programme. COVID-19 will double number of people facing food crises unless swift action is taken [online], 2020. Available: https://www.wfp.org/news/covid-19-will-double-numberpeople-facing-food-crises-unless-swift-action-taken

28 The World Bank. Food security and COVID-19 [online]. Available: https://www.worldbank.org/en/topic/agriculture/brief/food-securityand-covid-19 [Accessed 15 May 2020].

29 United Nations Population Fund. Pandemic and rising tide of violence increase demand for mental health, psychosocial care [online]. Available: https://www.unfpa.org/news/pandemic-andrising-tide-violence-increase-demand-mental-health-psychosocialcare

30 Jewkes R, Morrell R. Hegemonic masculinity, violence, and gender equality. Men Masc 2018;21:547-71.

31 Jewkes R, Morrell R. Gender and sexuality : emerging perspectives from the heterosexual epidemic in South Africa and implications for HIV risk and prevention, 2010: 1-11.

32 Cain M, Khanam SR, Nahar S. Class, patriarchy, and women's work in Bangladesh. Popul Dev Rev 1979;5:405.

33 Muderedzi J, Eide $\mathrm{AH}$, Braathen $\mathrm{SH}$, et al. Exploring the relationship between food insecurity, gender roles and HIV/AIDS among Tonga carers of disabled children of Binga in Zimbabwe. Sex Cult 2019;23:1131-46.

34 Kamali A, Nsubuga RN, Ruzagira E, et al. Heterogeneity of HIV incidence: a comparative analysis between fishing communities and in a neighbouring rural general population, Uganda, and implications for HIV control. Sex Transm Infect 2016;92:447-54.

35 Uganda Bureau of Statistics (UBOS) and ICF. Uganda demographic and health survey 2016. Kampala, Uganda and Rockville, Maryland, USA: UBOS and ICF, 2018.

36 Statistics UB of. National Population and Housing Census 2014 Main Report, 2014.

37 Uganda Ministry of Health. Uganda national policy guidelines for HIV voluntary counselling and testing. Kampala: Ministry of Health, 2003. 
38 Ballard TJ, Kepple AW, Cafiero C. The food insecurity experience scale: developing a global standard for monitoring hunger worldwide. technical paper. Rome, FAO, 2013. Available: http://www.fao.org/ economic/ess/ess-fs/voices/en/

39 Bickel G, Nord M, Price C. Guide to measuring household food security. Prepared by Bickel, Bickel Gary Mark, Nord Cristofer, Price William, Hamilton and John, Cook 2000;82.

40 Roberts TA, Auinger P, Klein JD. Intimate partner abuse and the reproductive health of sexually active female adolescents. J Adolesc Health 2005;36:380-5.

41 Raj A, Santana MC, La Marche A, et al. Perpetration of intimate partner violence associated with sexual risk behaviors among young adult men. Am J Public Health 2006;96:1873-8.

42 Mullinax M, Grilo SA, Song XS, et al. HIV-risk behaviors of men who Perpetrate intimate partner violence in Rakai, Uganda. AIDS Educ Prev 2017;29:527-39.

43 Chirwa ED, Sikweyiya Y, Addo-Lartey AA, et al. Prevalence and risk factors of physical or sexual intimate violence perpetration amongst men in four districts in the central region of Ghana: baseline findings from a cluster randomised controlled trial. PLoS One 2018;13:e0191663.

44 Fleming PJ, Mccleary-sills J, Morton M, et al. Risk factors for men' $s$ lifetime perpetration of physical violence against intimate partners : results from the international men and gender equality survey (IMAGES) in eight countries, 2015: 1-18.

45 Palermo T, Bleck J, Peterman A. Tip of the iceberg: reporting and gender-based violence in developing countries. Am J Epidemiol 2014;179:602-12.

46 Yount KM, Higgins EM, VanderEnde KE, et al. Men's perpetration of intimate partner violence in Vietnam. Men Masc 2016;19:64-84.

47 Cardoso LF, Gupta J, Shuman S, et al. What factors contribute to intimate partner violence against women in urban, conflict-affected settings? Qualitative findings from Abidjan, Côte d'Ivoire. J Urban Health 2016:93:364-78.

48 Lentz EC. Complicating narratives of women's food and nutrition insecurity: Domestic violence in rural Bangladesh. World Dev 2018:104:271-80
49 Culbreth R, Swahn MH, Salazar LF, et al. Intimate partner violence and associated risk factors among youth in the slums of Kampala. $J$ Interpers Violence 2019:088626051988992.

50 Swartout KM. The company they keep: how peer networks influence male sexual aggression. Psychol Violence 2013;3:157-71.

51 Coomber K, Mayshak R, Liknaitzky P, et al. The role of illicit drug use in family and domestic violence in Australia. $J$ Interpers Violence 2019:088626051984328

52 Stark L, Seff I, Hoover A. Sex and age effects in past-year experiences of violence amongst adolescents in five countries. PLOS One 2019;14:e0219073.

53 Mckool M, Stephenson R, Winskell K, et al. Case for a social norms approach, 2019.

54 Abramsky T, Devries K, Kiss L, et al. A community mobilisation intervention to prevent violence against women and reduce HIV/ AIDS risk in Kampala, Uganda (the SASA! study): study protocol for a cluster randomised controlled trial. Trials 2012;13:96.

55 Promundo, CulturaSalud, and REDMAS. Program P - a manual for engaging men in Father- hood, caregiving, maternal and child health. Promundo: Rio de Janeiro, Brazil and Washington, D.C. USA. these materials can be reproduced provided credit is given 2013.

56 Lindberg LD, VandeVusse A, Mueller J. Early impacts of the COVID-19 pandemic: findings from the 2020 Guttmacher survey of reproductive health experiences. New York Guttmacher Institute; 2020. https://www.guttmacher.org/report/early-impacts-covid-19pandemic-findings-2020-

57 World Food Program. COVID-19 level 3 emergency: external situation report no.17, 2020

58 Rose DD. Interventions to reduce household food insecurity: a synthesis of current concepts and approaches for Latin America. Rev Nutr 2008;21:159s-73.

59 Bourey C, Williams W, Bernstein EE, et al. Systematic review of structural interventions for intimate partner violence in low- and middle-income countries: organizing evidence for prevention. $B M C$ Public Health 2015;15:1165. 